\title{
Social Prospects of Post-Sports Adaptation in the Neo- Industrial Economy
}

\author{
Petr Ryskin*, Stanislava Fagina, Natalia Shuraleva
}

\author{
Ural State University of Economics, Ekaterinburg, Russia \\ ${ }^{*}$ Corresponding author.Email: aduvv@mail.ru
}

\begin{abstract}
The relevance of the research lies in the need to determine the prospects for post-sports adaptation from the standpoint of public institutions and the formulation of recommendations that take into account the peculiarities of post-sports adaptation in the neo-industrial economy. From the point of view of sociological theory and methodology, the problem of professional sports is to determine the characteristic group characteristics of professional athletes, acquired by them in the process of socialization. The results of the study make it possible to formulate directions for the modification of public institutions, which will provide psychological and educational assistance and support in terms of social adaptation of retiring sports professionals, as well as provide opportunities to plan a further career, help with non-sports education and employment.
\end{abstract}

Keywords: post-sport adaptation, social institutions, neo-industrial economy.

\section{INTRODUCTION}

The main feature of the social group of professional athletes is engaging in various sports, therefore, it is necessary to analyze the phenomenon of sport as a social phenomenon and social practice, a social institution within which the reproduction and development of social relationships related to sports takes place. From the perspective of sociology, institutional-group sports practices, on the one hand, implement a wide range of social functions, on the other hand, they are a massive process of socialization [1]. Professional sport provides the basic elements of institutionalization, such as the rules and norms directly, the subjects-carriers of these norms, as well as the organization and community of people [2].

Such a position often connects the development of a particular phenomenon in society, including sports, with a set of rules governing sports as a real practice of social everyday life [3]. For example, E. Durkheim emphasized that "social behavior is always governed by a certain set of rules that are both obligatory and attractive, necessary and desirable" [4].

Sport as an institutionalized social practice [5] forms a community of "language", ideals, values, beliefs, moral norms, stereotypes of behavior, as well as certain roles and uniquely understood situations and actions.
Becoming a member of a sports social group, a person assimilates sports norms and integrates into the social system of sports relations [6].

The social sphere of sports, including the professional one, provides ample opportunities for self-presentation, status positioning, performativity [7], individualization and experience of life space and time [8]. Professional sports are becoming an essential part of the modern show industry, going beyond the cultural and gaming spheres and turning social sports practices into a commodity. Moreover, as D. Bogdanova notes, the integrative processes, the process of genesis, the transformation of professional sports, coupled with changes in the social context of its existence, modified it into a media construct, a performative practice implemented in the construction of global sports events [9].

Professionalization of sport, as its main social-group feature, presupposes:

- firstly, the presence of specific social norms and prescriptions that regulate the behavior of athletes in the framework of sport;

- secondly, the entry of an athlete through sport also into the broader structure of society (going beyond the framework of "pure sport"), which, on the one hand, provides an athlete with the opportunity to comfortably satisfy basic social status needs through sports, 
accumulation of "sports baggage" as "social capital" - if it chooses the "profession of an athlete" or another profession in the "sports field", and on the other, it allows society to realize social control over the development of sports in general and sports practices, as well as the behavior of athletes, etc.

\section{METHODS}

In 2012, 2015, 2020 within the framework of a series of mass surveys with a target sample, depending on the sporting rank, we interviewed a total of 2,350 respondents in more than 80 types of sport, which, for convenience, we grouped into three main subgroups, depending on the sport:
a) play, group;
b) martial arts;
c) individual, paired.

Research hypothesis. The professional status of athletes in Russia has not been fully formed. There are various deformations associated with an incorrect understanding in society of an amateur and a professional athlete. Each of the presented sports has its own specificity, which determines the nature and direction of post-sports adaptation.

The study involved athletes at various stages of their professional careers:

— at the beginning of a professional career;

— professionals at the peak of their skills;

- as well as those of the professionals who have decided to complete or have already completed their sports career.

\section{RESULTS}

Despite the stabilization of the socio-political and economic situation in our country over the past two decades of the sports industry development, as well as the entertainment industry, the hierarchy of problems of professional athletes associated with the end of a sports career has remained practically unchanged. The invariability of the problem field of professional athletes is determined by its sectoral (professional and sports) nature.

Social prospects and difficulties of leaving professional sports are expressed in the strategies of postsports life of professional athletes. A professional athlete forms a strategy based on life plans, expected problematic moments of other features of sports life. Accordingly, having analyzed the composition of life plans, problems and prospects of stable life after the end of an athlete's career, it is possible to form key strategies of post-sports life.
As polls have shown, the life plans of professional athletes are aimed at the following, table 1

Table 1. Life plans of professional athletes.

\begin{tabular}{|l|l|l|l|}
\hline Life plans & 2020 & 2015 & 2012 \\
\hline $\begin{array}{l}\text { Continuation of a sports } \\
\text { career, but in a different status }\end{array}$ & $42 \%$ & $45 \%$ & $37 \%$ \\
\hline $\begin{array}{l}\text { To retrain, change the type of } \\
\text { activity }\end{array}$ & $13 \%$ & $32 \%$ & $38 \%$ \\
\hline $\begin{array}{l}\text { Maintain / ensure a high level } \\
\text { of income, find a high-paying } \\
\text { job }\end{array}$ & $11 \%$ & $30 \%$ & $27 \%$ \\
\hline
\end{tabular}

A comparative analysis of the data from surveys conducted at different times showed that institutional attachment to the field of sports is complemented here by a significant improvement in the conditions for engaging in professional sports over the past few years (an increase in salaries / fees, an improvement in the training base, etc.). In general, we can say that the plans of a professional athlete have been determined, because he does not seek to rely on an uncertain case, to "seize the moment" in order to arrange his life after leaving professional sports. Only $3 \%$ of the respondents chose the appropriate answer option.

So, the post-sports life plans of professional athletes boil down to the fact that they plan to continue their career in sports, changing their professional status, "finish their studies" and find a high-paying job, or "go with the flow", "seize the moment", "agree to any profitable offer".

The nature of the post-sports life of professional athletes in the neo-industrial economy is determined by the following factors:

- the factor of unsystematicity associated with the lack of a nationwide system for ensuring the process of post-sports rehabilitation and social adaptation of professional athletes, the social monofunctionality of athletes, their increased social-status expectations, etc .;

- a pronounced social monofunctionality of a professional athlete, his "social infantilism", which is understood as the absence of a professional athlete's knowledge and experience of an extra-sports nature, which would provide him with effective post-sports adaptation in society in a different social and professional status;

- heightened social expectations, ambitions, when we can talk about the psychological difficulties of a professional athlete associated with the need to rebuild his own career, to gain a high social position, an acceptable social status for him in a different social and professional role;

- "resentment" against the state and the infrastructure of professional sports, for the fact that they obviously do not create conditions for "transition" from the sports sphere to the non-sports one. Resentment is 
expressed in psychological tension, fatigue and negative, often "decadent" moods among professional athletes, which is often the basis of their deviant behavior.

The study clearly showed that a professional athlete in most cases is not able to independently design and implement his life strategy, since he does not have the necessary communication skills. In the context of professional sports, this "inability" is literally cultivated, since the vital independence and strategic makeup of the personality of a professional athlete allegedly "prevent him from concentrating on the production of a sports result".

Thus, a professional athlete turns out to be socially, and everyday insolvent, not being able to solve the pressing problems of determining his place in society.

The modern Russian sports industry and infrastructure are arranged in such a way that an athlete produces a sports result, and all other issues - housing, food, leisure, clothing, and others - are decided by coaches, a club, a sports association, sponsors, patrons, etc. A Russian professional should not think about anything other than a sports result.

It can be stated that the main acquired quality of a professional athlete is his inconsistency, which is the result of the competencies formed within the framework of professional and sports socialization.

\section{CONCLUSION}

Based on the analysis of the problems and difficulties of post-sports adaptation of professional athletes, carried out in the work, we will further offer a number of recommendations for increasing the social efficiency of the process under study. Accordingly, further we will answer the question of what measures should be taken in the state and society to facilitate the process of post-sport adaptation of professional athletes?

First of all, we note that the recommendations can be attributed to the activities of three main social institutions that determine the nature of the process under study: the state represented by public authorities, the industry of professional sports, federations, etc., as well as civil institutions represented by human rights and other public organizations, professional associations of athletes.

Recommendations for public authorities:

- firstly, the main problem is the lack of a formal professional and labor status of athletes who go in for sports on a professional basis. In this regard, the state must create regulatory conditions for the official employment of athletes. Today athletes, according to the tradition of the USSR, are amateurs and are forced to find jobs as coaches, to be "listed" in non-sporting positions in various organizations. As a result, in terms of social rights and guarantees, in terms of their professional work, athletes are unprotected. In addition, after retiring from professional sports, athletes do not receive pension benefits. Since the employer of professional athletes is both state (municipal) structures and non-state - sports clubs, the state must create conditions, in an active and passive form, to provide assistance and oblige clubs to officially register athletes for their main occupation with a corresponding entry in the employment history, providing social and pension contributions, the possibility of preferential medical care in specialized medical institutions. In addition, it is necessary to legislatively determine the length of service of professional athletes in order to ensure their retirement;

- secondly, it is possible to recommend the creation of conditions for building a whole system of post-sports adaptation of professional athletes - psychological assistance institutions, educational institutions and programs of additional professional education for advanced training and retraining of former professional athletes. Since the system of post-sports adaptation itself is formed within the framework of sports and educational structures, the state can only create conditions regulatory, organizational, stimulating - for its emergence and further development. In fact, it is the state that should initiate the formalization of the professional and labor status of athletes professionally speaking for their country.

Recommendations for representatives of the sports industry:

In accordance with state support, as well as on an independent initiative, clubs, federations and other sports organizations should contribute to the formal consolidation of an athlete's professional status. To fix his activities, conditions of implementation, remuneration, labor rights, obligations and guarantees with an employment contract. In this part, appropriate legal entities must be established that will act as employers for professional athletes. The bottom line is that a professional athlete is officially engaged in sports activities, receiving his material reward for this. Consequently, employment should be official and in the specialty.

\section{Recommendations for public organizations:}

Athletes must create precedents for the aggregation and articulation of their own interests - professional, postsports and others. It is necessary to create public human rights organizations of professional athletes, non-state support funds, public educational organizations, and trade unions.

The formulated recommendations, in our opinion, will largely solve a number of problems of post-sports adaptation of professional athletes. 


\section{REFERENCES}

[1] T. Alkemeyer, Sociology of sport. The bodily practices of subjectivation and self-enactment. Logos, 3 (2006).

[2] T. Parsons, The system of modern societies. Prentice Hall, 1971.

[3] M. Moss, Society. Exchange. Personality: Works on social anthropology. Oriental literature, 2016.

[4] E. Durkheim, Sociology. Its subject, method, purpose. Canon, 1995.

[5] P. Bourdieu, Sociology of social space. Institute for Experimental Sociology Aletheia, 2005.

[6] W. Donald, Harper Structural-Functionalism: Grand Theory or Methodology? School of Management University of Leicester, 2018.

[7] L. J. D. Wacquant, The social logic of boxing in black Chicago: Toward a sociology of pugilism. Sociology of Sport Journal, 3 (1992).

[8] H. Eichberg, Body Cultures: Essays on Sport, Space and Identity. Routledge, 2005.

[9] D. Sh. Bogdanova, Professional sports in modern society: culture-philosophical analysis: Synopsis of the dissertation of the candidate of philosophical sciences. SPb., 2013. 